\title{
DETERMINATION OF TOTAL BODY FAT BY ABSORPTION OF AN INERT GAS; MEASUREMENTS AND RESULTS IN NORMAL HUMAN SUBJECTS *
}

\author{
By GERSON T. LESSER, WILLIAM PERL AND J. MURRAY STEELE \\ (From the New York University Research Service, Goldwater Memorial Hospital, and the \\ Department of Medicine, New York University, New York, N. Y.)
}

(Submitted for publication June 16, 1960; accepted August 11, 1960)

The usefulness of the concept of a "fat-free lean mass" (FFLM $)^{1}$ has been widely appreciated (2-6). Such a concept involves a consideration of the mammalian body as a sum of two major components : $a$ ) the body fat, which varies widely from individual to individual and which may also vary in a given individual from time to time depending upon his state of nutrition; and $b$ ) the FFLM which is of relatively constant weight in a given healthy individual and of relatively constant composition in the various mammalian species except perhaps for the proportion of bone. Since the concentrations of protein, water and electrolytes in the FFLM vary only slightly, it is the difference in fat content which leads to wide variations in these concentrations in the whole body. This observation was made for individual tissues in 1937 by Hastings and Eichelberger (7).

A knowledge of the relative proportions of these two major components of the body is of obvious biological interest. It has been suggested that the FFLM, rather than body weight or surface area, should be used as a primary reference standard for various purposes $(8,9)$. Similarly, total body fat would seem to be fundamentally involved in the action and distribution of various substances

* This work was supported in part by grants from the United States Public Health Service, Bethesda, Md. (H-1288), and by the Mona Bronfman Sheckman Foundation.

1 "Lean body mass" has been variously defined to include differing small amounts of "essential" lipids. Since "essential" lipids are at most a small fraction of this mass, confusion might be avoided if the term "fat-free lean mass" is used to describe body weight minus total body fat. Total body fat is defined as the weight of all ether-extractable material in the body. It is not to be confused with "adipose tissue" which, in addition to fat, contains variable small amounts of water and other constituents. This definition of FFLM is considered synonymous with the term "fat-free body" used by Keys and Brozek (1). in the body, such as fat-soluble drugs and anesthetics. Moreover, in recent years it has become increasingly apparent that adipose tissues are metabolically active and knowledge of total body fat could add significance to various studies in fat metabolism.

FFLM contains approximately 72 per cent water $(10-12)$; the variation in this concentration is probably small [Keys and Brozek, in a review article (1), feel the standard deviation is about 3 per cent]. Total body water is subject to direct measurement by the dilution of antipyrine (13), deuterium or tritium. From this measurement and a simple calculation (total body water/0.72), an estimate of the FFLM can be obtained. If this value is subtracted from total body weight, the remainder may be assumed to be body fat.

Total body fat measurements have been attempted by various other methods in living animals $(1,14)$. In recent years, perhaps that most widely used for physiologic investigation has been densitometry, either alone or (14) combined with body water measurements.

Our fundamental purpose in measuring body fat has been to provide a means of studying the water content of the FFLM under conditions of abnormal hydration or nutrition, and the changes that may occur with age. Under such abnormal conditions, the necessary assumptions underlying calculation of body composition from either densitometry or body water measurements, and probably also of the combined measurement, are open to question. It was essential, therefore, to develop a method that would measure fat more directly and largely independently of the size or condition of the FFLM. In 1935, Shaw, and Behnke and their co-workers $(15,16)$ attempted such an independent method by washout of dissolved body nitrogen. Since nitrogen is quite lipid-soluble, the volume of nitrogen dissolved in body tissues 
is largely a function of the amount of fat present. However, the method is subject to appreciable error and is difficult to execute. Utilizing the same principle, many of the errors and technical difficulties of the nitrogen elimination method might be avoided if a nontoxic, inert foreign gas with a much greater fat/water solubility ratio is employed. The widely used and relatively safe anesthetic gas, cyclopropane, was known to be highly fat-soluble. Measurement of the volume of cyclopropane absorbed from a closed respiratory system proved satisfactory for the determination of total body fat in living rats $[ \pm 5$ per cent compared with extraction of dried tissues with ether (17)]. Cyclopropane absorption in human subjects, however, presents a difficulty. Equilibration of the gas with body tissues was found to be considerably slower than in rats. Small amounts of gas were still being absorbed after eight hours. It became necessary, therefore, to find some way to circumvent this problem.

In the normal subjects, a mathematical procedure has been utilized to extrapolate observed absorption data to obtain equilibrium absorption values and, from these, reasonably accurate values for total body fat. The present report includes experimental observations on a group of normal subjects. The derived values for fat-free lean mass are sufficiently accurate to lend themselves to use in investigation of changes in this body compartment.

\section{METHODS}

\section{Apparatus and experimental procedure}

A circular rubber diaphragm (D) (Figure 1) with a central aperture somewhat less than collar size was slipped over the subject's head and snugly fitted to the neck just above the larynx. The head was then introduced into a cylindrical Plexiglas helmet $(\mathrm{H})$, the outer border of the diaphragm being brought over the entire lower lip of the helmet and made airtight with a large rubber band (R). Sufficient glycerol was poured into the helmet through a stopcock (A) to form a coating and seal over the diaphragm. All stopcocks were then turned to provide a completely enclosed gas system involving head and neck of the subject, the helmet, a soda lime container (SL), an airtight pump (P) and a Tissot spirometer (SP) adapted with an additional inlet to enable a continuous circular flow of gases. All seals were coated with a glycerol-starch grease, the pump was lubricated with glycerol, and flexible copper (FCT) or Compar plastic tubing was used throughout because of

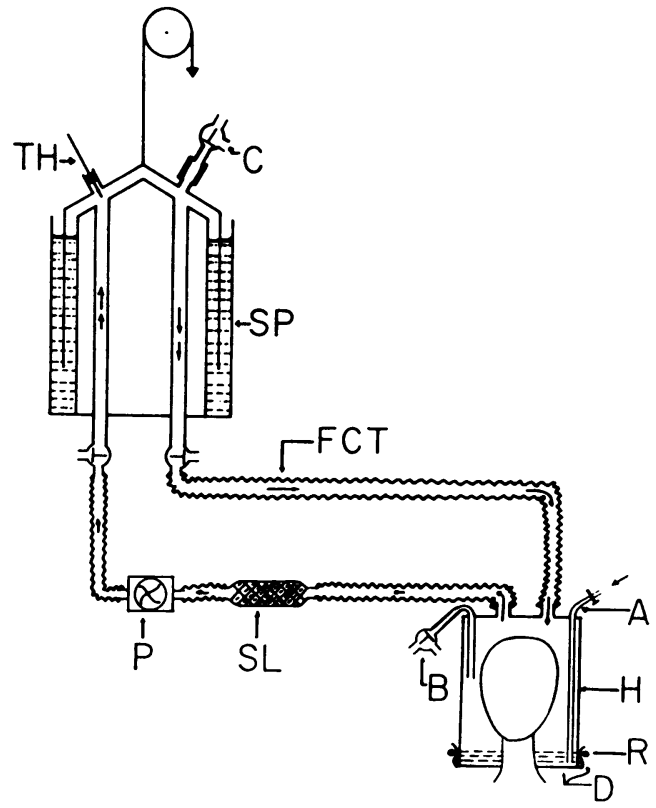

Fig. 1. Diagram of Closed respiratory CIRCUit For STUDIES OF ABSORPTION OF INERT GAS IN MAN. See text for explanatory details.

the solubility and diffusibility of cyclopropane into and through rubber (18), most greases and oils and most commercially available plastics (Lesser and Blumberg, unpublished data).

The entire system was flushed and filled with pure oxygen and the Tissot bell brought to the desired level. Gas volumes of the total system were from 18.5 to $21.0 \mathrm{~L}$ for experiments done at "small respiratory circuit volume" and from 160 to $250 \mathrm{~L}$ for "large respiratory circuit volume" experiments. A known small volume of pure cyclopropane was introduced rapidly from a calibrated gas buret through stopcock $\mathrm{C}$ and zero time was assumed to be 30 seconds later (small volume) and 90 seconds later (large volume) than the mid-point of the addition. The initial concentration (between 1 and 2 per cent) was well below anesthetic level and no pharmacologic effects were observed. At stated time intervals thereafter samples were taken from stopcock B into gas burets. Total gas volume of the system and of the subject's lungs had been previously measured and was maintained constant throughout (within $0.2 \mathrm{~L}$ ) by continued addition of oxygen through stopcock C.

All gas samples were analyzed for cyclopropane content by a modification (17) of the method of Robbins $(19,20)$. With proper care in the hands of a trained technician, consistent recoveries ( \pm 1 per cent) are obtainable.

\section{Description of calculation}

The values necessary for the calculation of body fat from the amount of cyclopropane absorbed were determined as follows. 
Gas volume of the closed system including the subject's lungs. A method was developed for accurate estimation of this volume and was carried out for each subject prior to the body fat procedure. It involved flushing the apparatus with oxygen, noting the spirometer wheel reading and temperature, sampling the contained gas and then rapidly adding a large known volume of pure nitrogen. After mixing of gases had taken place, temperature and spirometer volume readings were again recorded and samples taken for analysis. "Dead space" volume was then determined in standard fashion:

$$
\begin{array}{r}
{\left[\begin{array}{c}
\text { initial vol. } \\
\text { reading } \\
+ \text { dead space }
\end{array}\right]\left[\begin{array}{c}
\text { initial } \\
\mathrm{N}_{2} \\
\text { conc. }
\end{array}\right]+\left[\begin{array}{c}
\text { vol. of } \\
\mathrm{N}_{2} \\
\text { added }
\end{array}\right]\left[\begin{array}{c}
\text { conc. of } \\
\mathrm{N}_{2} \\
\text { added }
\end{array}\right]} \\
=\left[\begin{array}{c}
\text { final vol. } \\
\text { reading } \\
+ \text { dead space }
\end{array}\right]\left[\begin{array}{c}
\text { final } \\
\mathrm{N}_{2} \\
\text { conc. }
\end{array}\right] .
\end{array}
$$

Since the amounts of nitrogen involved were large (about $60 \mathrm{~L}$ ), the error due to loss or gain of dissolved body $\mathrm{N}_{2}$ was insignificant. A minor correction for this was made in the calculation. Repeated volume determinations with the same subject in the system agreed within $0.2 \mathrm{~L}$, and agreed closely with the dead space air volume of the apparatus alone, adding the measured functional residual air of the subject and subtracting the volume of the subject's head and neck. To the "dead space" volume determined in this fashion, the volume of gas in the bell of the Tissot spirometer was added, the total being termed the "respiratory circuit volume."

Volume of cyclopropane added to system at beginning of experiment. Standard calibrated gas burets were used throughout. Between 200 and $600 \mathrm{ml}$ of pure cyclopropane was added, depending upon an estimate of the subject's fat content and upon the experimental respiratory circuit volume.

Pressure. The pressures in various portions of the closed system with a subject in position were measured on numerous occasions. Due to the action of the pump, gases contained on the "low pressure" side of the system (soda lime container, helmet, subject's lungs and connecting tubing) remained at $2.5 \mathrm{~mm} \mathrm{Hg}$ below atmospheric pressure. Gas in the spirometer was always at approximately atmospheric pressure, the average pressure for the entire system therefore being approximately $1.5 \mathrm{~mm} \mathrm{Hg}$ below atmospheric pressure at all times.

Temperature. Temperature of the gases in the respiratory system was recorded at each sampling time. Temperature of each sample was recorded when reading of buret volume was made.

Solubility coefficient. The solubility coefficients for cyclopropane in fat were determined in a Warburg apparatus and corroborated by a tonometer method and also by extraction of gas from fat samples previously equilibrated with pure cyclupropane. The solubility coefficients ( $\mathrm{ml}$ gas STP per $\mathrm{g}$ fat) for cyclopropane are 10.84 at $37^{\circ}$ and 11.81 at $34^{\circ} \mathrm{C}$. These studies were done on ether extracts of rat carcasses (21) and have since been repeated on a few samples of human fat, essentially similar values being obtained (Nidus and Lesser, unpublished observations).

Since gas solubility varies with temperature, mean temperature of body fat must be estimated for each subject. This figure is difficult to obtain with great accuracy, as different portions of the body vary to some extent (22-24). In smaller animals rectal temperature is normally 1 to $2^{\circ}$ above that of the body as a whole (23) ; in man, the temperatures of arterial, mixed venous blood and muscle are 0.5 to $2^{\circ}$ below that of the rectum $(22,24)$. For the calculation in these experiments a solubility coefficient of $11.26 \mathrm{ml} \mathrm{STP}$ gas per $\mathrm{g}$ lipid was used, corresponding to an average temperature for body lipids of approximately $36^{\circ} \mathrm{C}$. An error of $1^{\circ}$ in this estimate would result in an error of somewhat less than 3 per cent in the total body fat calculation.

Cyclopropane dissolved in nonlipid tissues. A minor correction must be made in the calculations for cyclopropane contained in body fluids and nonlipid tissues. From the body habitus of each subject an estimate was made of the size of the FFLM. The solubility of cyclopropane in nonlipid tisşues was studied and has been discussed in some detail in an earlier publication (17). For purposes of gas solubility, the FFLM was viewed as a polyphasic system containing $29 \mathrm{~g}$ of protein per $100 \mathrm{ml}$ of iso-osmotic saline. From available data, it has been estimated that at body $\mathrm{pH}$ and $36^{\circ} \mathrm{C}$ such a system would have a solubility coefficient of about 0.33 $\mathrm{ml}$ cyclopropane STP per $\mathrm{g}$ of FFLM.

Such estimates give merely an approximation of the cyclopropane absorbed by nonlipid tissues. However, due to the high fat/water solubility ratio for cyclopropane under equilibrium conditions, 85 to 95 per cent of cyclopropane in the normal body is contained in the fat. An error as great as 30 per cent in estimating the size and solubility coefficient of nonlipid tissues would therefore result in an error of only 2 to 5 per cent in the value obtained for body fat.

Calculation of total body fat. Observation of the amount of cyclopropane which remains unabsorbed in the system when gaseous equilibrium has taken place between body tissues and the cyclopropane in the system will be discussed in some detail below.

Once these values have been obtained the calculation itself is relatively simple:

ml cyclopropane at STP
absorbed by the subject $=$ added to the system at
at equilibrium
zero time

$\mathrm{ml}$ cyclopropane at S'TP remaining in the system in free gaseous phase at equilibrium.

Correcting the total volume of cyclopropane in the animal for that contained in nonlipid tissues: 


$$
\begin{aligned}
& \mathrm{ml} \text { cyclopropane } \mathrm{ml} \text { cyclopropane solubility coefficient for weight of } \\
& \text { at STP absorbed }=\text { at STP absorbed }- \text { nonlipid tissues at body } \quad \times \text { nonlipid } \\
& \text { by fat by the subject temperature and partial tissues } \\
& \text { pressure cyclopropane under } \\
& \text { equilibrium conditions }
\end{aligned}
$$

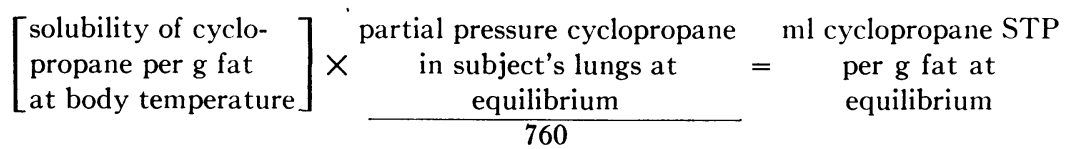

Total fat of subject $(\mathrm{g})=\frac{\mathrm{ml} \text { cyclopropane STP absorbed by fat }}{\mathrm{ml} \text { cyclopropane STP } / \mathrm{g} \text { fat at equilibrium }}$.

Corrections to STP are made throughout. Correction is also made for the small differences in cyclopropane concentration between the lungs and the external portion of the respiratory circuit, due to differences in water vapor and nitrogen concentration in these two regions. The assumption in these calculations that the cyclopropanefat system obeys Henry's law is supported by the results obtained by various methods of solubility estimation $(20$, 21).

In calculating fat values for the present experiments, the preceding equations and corrections were combined into a single formula, discussed in detail in the Appendix.

\section{OBSERVATIONS}

Cyclopropane absorption has been studied in 14 normal subjects by the method described; 26 experiments have been completed. In 11 of these, absorption was observed over approximately an 8 hour period. The absorption data of these prolonged experiments are tabulated (Table I) and discussed below.

The effect of body fat content on the rate and extent of absorption is readily apparent in three subjects of different body weight and habitus, who were studied over a shorter time period.

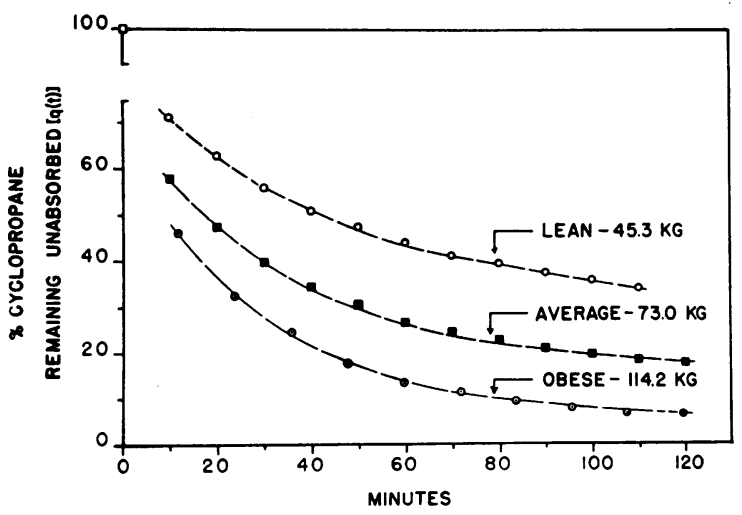

Fig. 2. Absorption of CyClopropane by three SUbJECTS OF DIFFERENT BODY WEIGHTS AND HABITUS. Experimental procedure was the same in all instances.

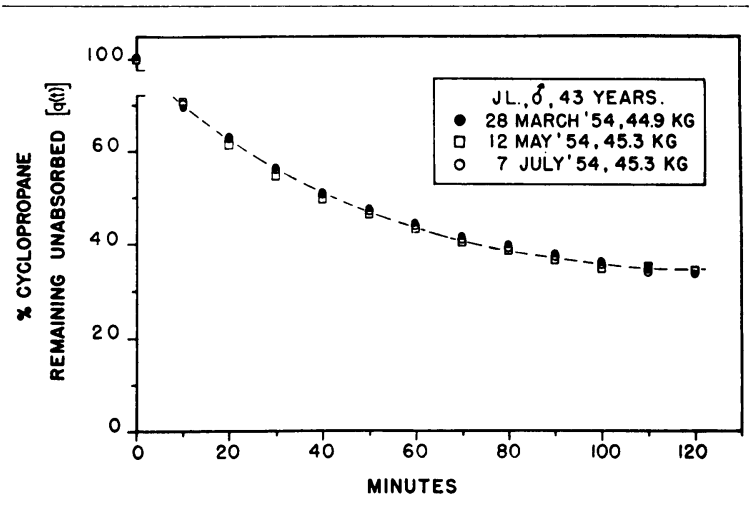

Fig. 3. Reproducibility of CYClopropane absorption in a subject at constant weights. Experimental procedure was the same in all instances.

After 110 minutes of absorption from a closed system a small lean man absorbed 65 per cent, a tall average man absorbed 75 per cent, and a small, very obese woman absorbed 95 per cent of the cyclopropane initially added (Figure 2 ).

The absorption curves in a given subject at con-

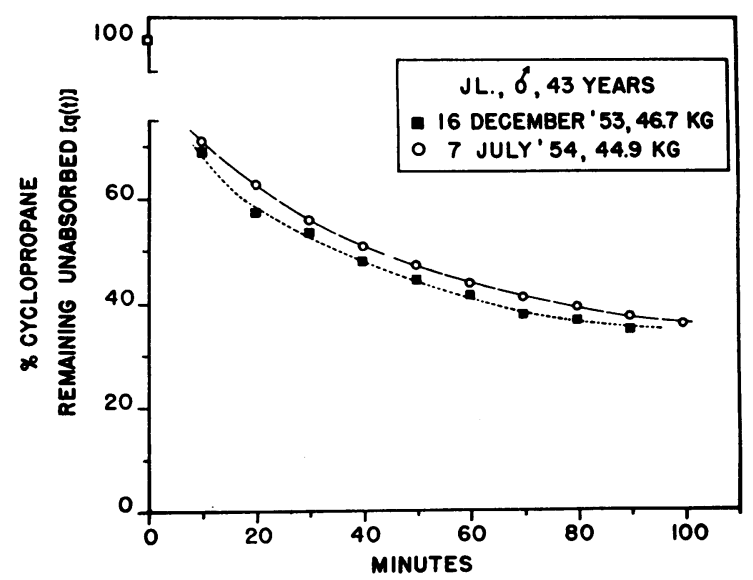

Fig. 4. Change in Cyclopropane absorption in a SUbJect With A SMALl CHANGE IN BODY Weight. Experimental procedure was the same in both instances. 
TABLE I

Observed cyclopropane uptake by human subjects; percentage of total cyclopropane in system remaining unabsorbed, $q(t)$, at time $t$

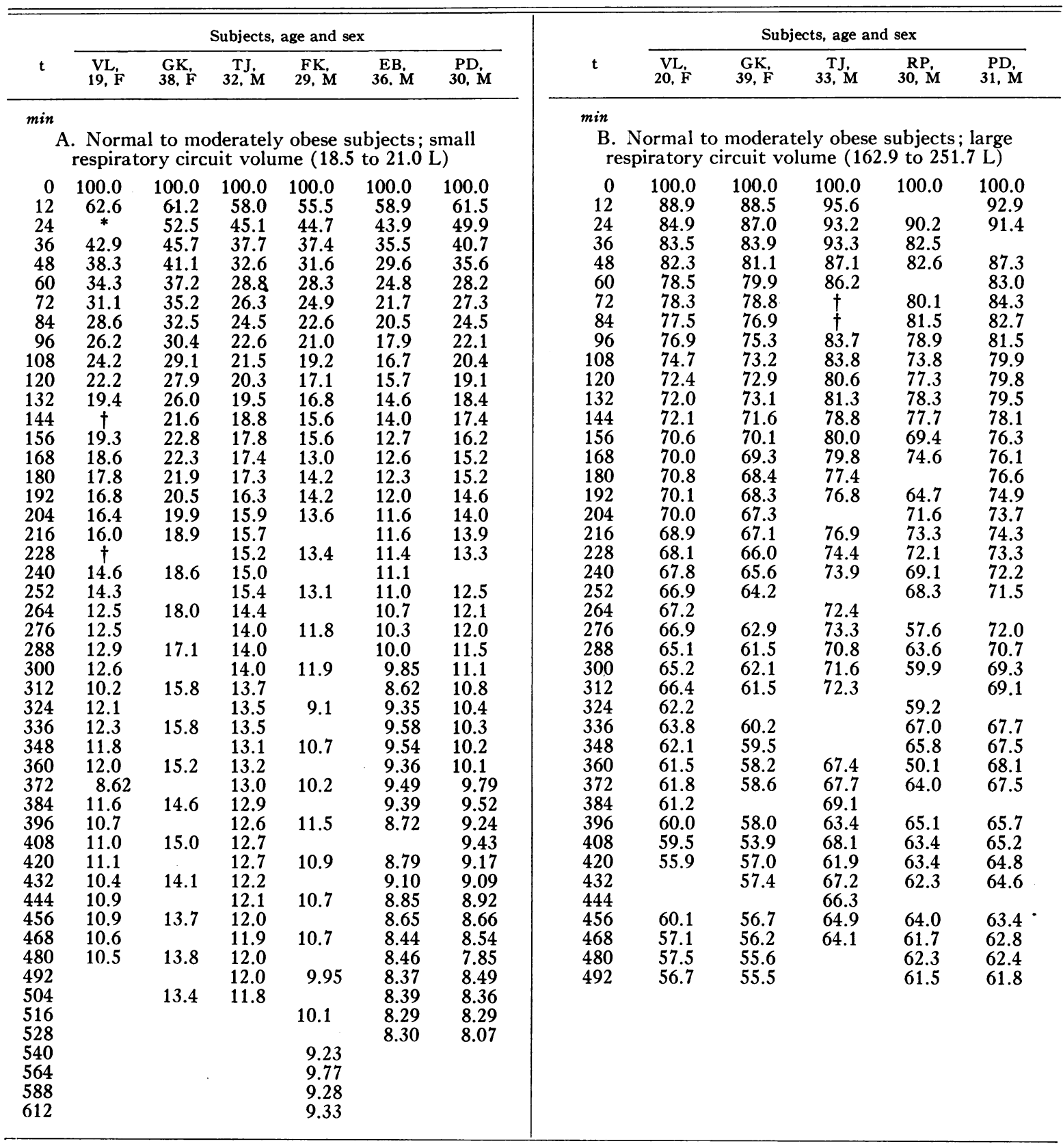

* Probable experimental error.

† Known experimental error. Blank spaces denote no sample taken.

stant weight are reproducible within very narrow limits. For example, one subject, when studied on three occasions over several months at weights of $44.9,45.3$ and $45.3 \mathrm{~kg}$, demonstrated variability of cyclopropane uptake of less than 2 per cent
(Figure 3). A similar degree of reproducibility was observed in any subject restudied under similar conditions. Subject JL was also studied at a slightly higher weight, presumably reflecting increased body fat content. This change appeared 


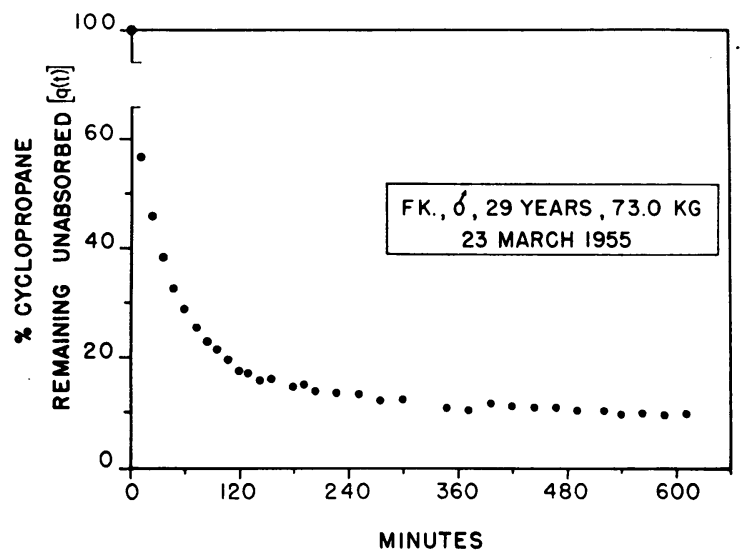

Fig. 5. Prolonged absorption of cyclopropane by A NORMAL SUBJECT.

to be sensitively reflected in the rate of cyclopropane absorption (Figure 4).

However, while gaseous equilibrium had essentially taken place between the environment and body tissues in the rat in 90 to 120 minutes (17), all human subjects were still absorbing cyclopropane after an 8 hour period (Table I and Figure $5)$.

Additional evidence of failure to reach essential equilibrium may be obtained by comparing the values obtained for total body fat by cyclopropane absorption with those for total body fat as calculated indirectly from total body water measure- ment, $\mathrm{F}(\mathrm{tbw}),{ }^{2}$ in the same subjects. If the observed value at 480 minutes on each absorption curve is assumed to be the "equilibrium" value and is used to calculate total body fat for the subject, $F(480)$, in every instance a smaller estimate of body fat is made by cyclopropane absorption than by $F$ (tbw). In normal to moderately obese subjects, the ratios between the values observed, $\mathrm{F}(480) / \mathrm{F}$ (tbw), vary from 0.56 to 0.93 (Table II). Similar analysis of these and other "normal" subjects when absorbing gas from a larger respiratory circuit volume showed even greater discrepancy between $F(480)$ and $F(t b w)$ values, indicating that cyclopropane absorption was less complete under these conditions (Table II).

It is therefore evident that an absorption period of as long as 8 hours is insufficient for gaseous equilibrium of cyclopropane to occur in human subjects under these experimental conditions. The discrepancy is systematic and becomes greater with larger volumes of the respiratory circuit. Thus, while ratios of the preceding type may possibly be useful as correction factors to estimate average body fat volumes in large groups of sub-

\footnotetext{
2 To avoid repetition of the phrase "total body fat as calculated from total body water" (antipyrine or tritium space), this value will be denoted as $\mathrm{F}$ (tbw). It is obtained as $F($ tbw $)=$ body weight $-\frac{\text { antipyrine (or tritium) space }}{0.72}$.
}

TABLE II

Total body fat calculated from "last point" on observed cyclopropane uptake curve compared with total body fat calculated from total body water

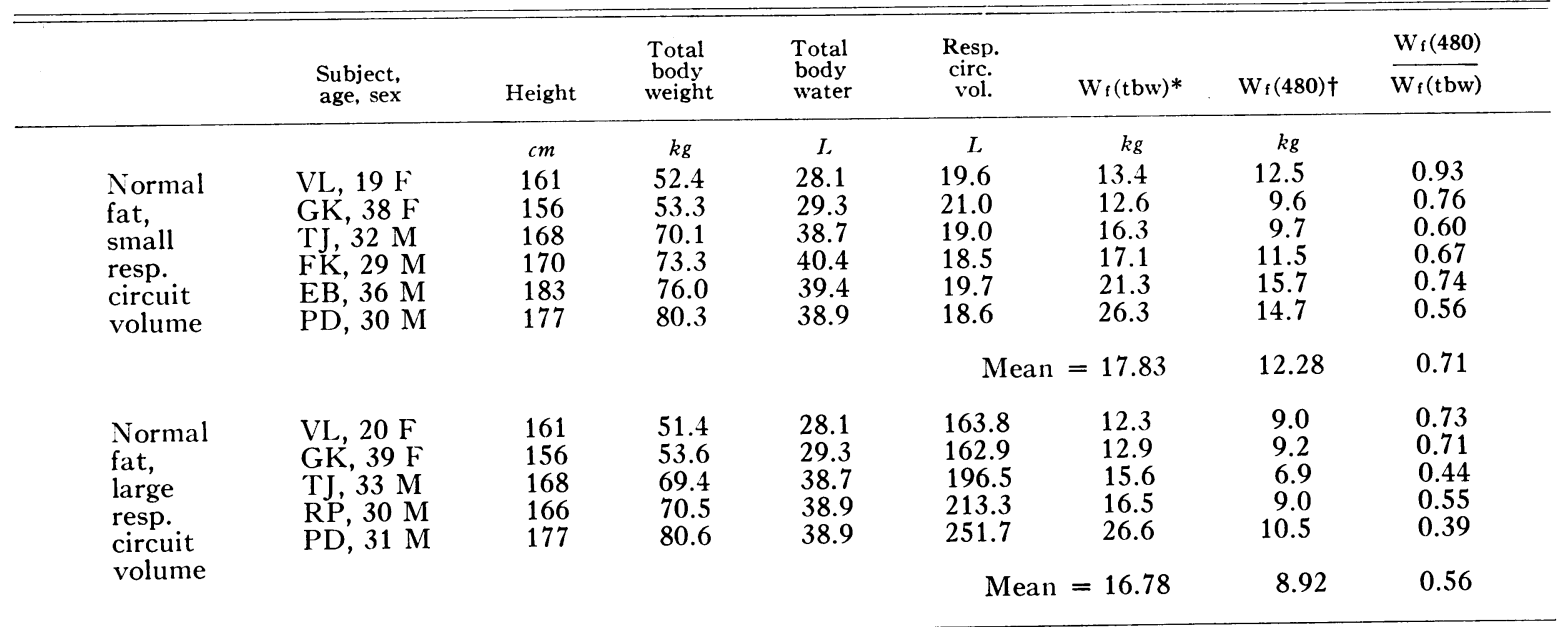

* $\mathrm{W}_{\mathrm{f}}(\mathrm{tbw})=$ total body fat from antipyrine or tritium space ( = total body weight - total body water/0.72)

$+W_{f}(480)=$ total body fat calculated from cyclopropane absorption, assuming that the 480 minute uptake value is equivalent to the equilibrium absorption $\left(q_{x}\right)$ value. 
jects, their use to estimate accurately the fat content of individuals is not justified.

Since absorption studies cannot feasibly be continued sufficiently long to measure the cyclopropane equilibrium value, $\mathrm{q}_{\infty}$, directly, the problem arose of calculating this value, necessary for the calculation of body fat, from the observed finite portions of the absorption curves actually measured. Such calculation is possible if a physically valid mathematical expression is fitted to the observed absorption curve and then extrapolated for a value of $t=\infty$. A reasonably exact theory of the dynamics of cyclopropane uptake by humans leading to manageable mathematical expressions has so far only been approximated.

Various expressions have been tested. The one utilized to extrapolate the present results conforms with generally held hypotheses for inert gas uptake and transport $(25,26)$. The quantity of inert gas in the total system (breathing circuit plus subject) is assumed to remain constant throughout. This is supported by evidence that cyclopropane is not significantly metabolized (17) or diffused through the skin (27). The enclosed breathing circuit is assumed to be in contact via the lungs and the arterial blood with the body tissues. The tissues are considered to be grouped into absorption "compartments," each supplied in parallel by the arterial blood (Figure 6). Each compartment is characterized by its capacity for absorbing the particular inert gas ("solubility volume") and by a specific blood flow rate. The compartments, of which the body adipose tissue may be identified as one or more, may not be strictly contiguous anatomical regions, but may be considered as "cyclopropane spaces." The few body tissues which do not conform to such a parallel arrangement probably absorb only small amounts

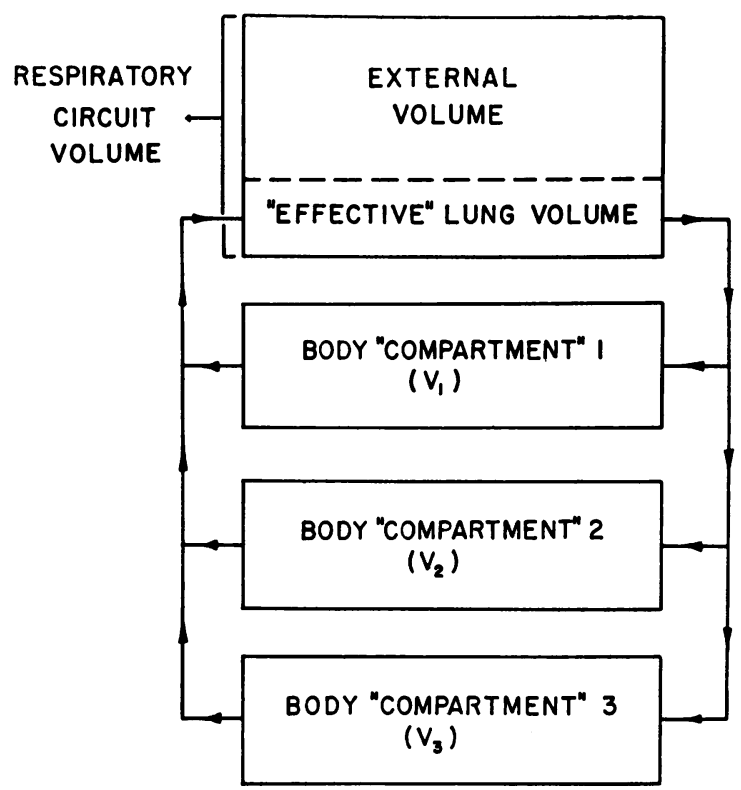

Fig. 6. Diagrammatic REPRESENTAtion of CyCloproPANE UPTAKE BY THE BODY. The system includes a "respiratory circuit volume" (external gas volume of the closed breathing circuit plus an effective lung volume), and some number of "cyclopropane space" body compartments. Each compartment can be defined by a mass, an average solubility coefficient for cyclopropane, and a blood flow.

of cyclopropane and should affect the over-all absorption process only slightly.

It is assumed that intratissue diffusion is so rapid in relation to the relatively slower rate of perfusion that intratissue mixing may be considered to be instantaneous, and also that only insignificant diffusion of the inert gas takes place across the surface boundaries of the neighboring tissues. It is further presumed that a steady physiological state exists throughout the course of the experiment. These assumptions permit fitting to the experimental absorption curves an expression of the form:

$$
q(t)=q_{\infty}+a_{1} e^{-k_{1} t}+a_{2} e^{-k_{2} t}+a_{3} e^{-k_{3} t}+\cdots
$$

where

$$
\mathrm{q}(\mathrm{t})=\frac{\text { concentration of cyclopropane in respiratory circuit volume (unabsorbed gas) at time, } \mathrm{t}}{\text { concentration of cyclopropane in respiratory circuit volume at } \mathrm{t}=0}
$$

and where $q_{\infty}$ is the limiting value of $q(t)$ as $t$ approaches infinity (see Appendix).

Existing graphical methods of fitting sums of exponential terms to the given curves were found to be inadequate in the present case. Accordingly, a semigraphical method for such fitting was developed and used (28). ${ }^{3}$ At each sampling time,

3 After completion of the present work the attention of the authors was drawn to a paper by Greville (29) in which decay-type data (glucose tolerance curves) were 
TABLE III

Total body fat calculated from exponential analysis of observed cyclopropane uptake curve compared with total body fat calculated from total body water

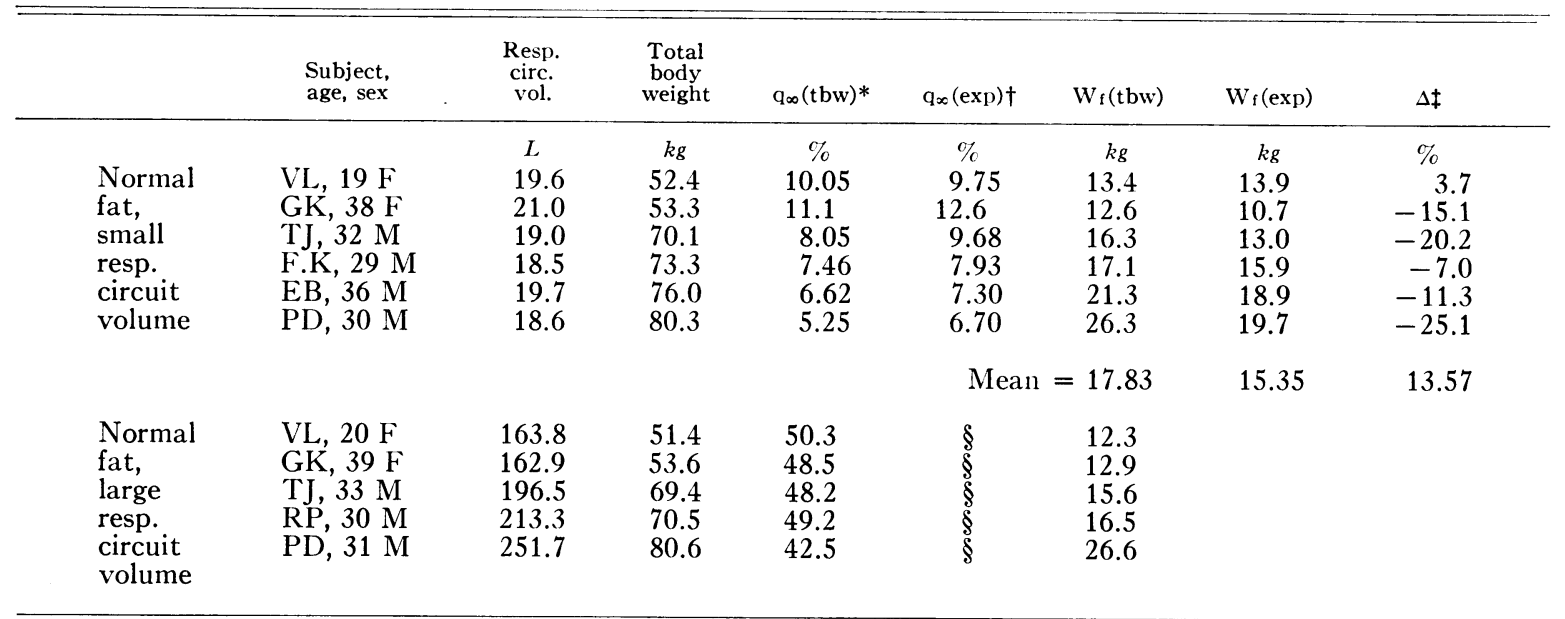

* Calculated from $W_{\mathrm{f}}($ tbw), Table II, by Equation [16] in Appendix.

$\dagger$ Extrapolated value by exponential curve-fitting (28).

$\ddagger \Delta=100\left[\mathrm{~W}_{\mathrm{f}}(\exp )-\mathrm{W}_{\mathrm{f}}(\mathrm{tbw})\right] / \mathrm{W}_{\mathrm{f}}($ tbw $)$.

$\S$ Analysis by exponential curve-fitting not possible (see text).

$t$, the first derivative (i.e., the tangent) of the observed $q(t)$ value may be plotted against the $q(t)$ value itself. This type of plot permits detailed inspection of the experimental data, particularly with reference to the possibility of exponential fitting. If at prolonged time, perhaps 4 to 8 hours of gas absorption, the remaining absorption data fall along a straight line on this plot, it may be assumed that the absorption process can be described as the decay of a single exponential over this time period. The straight line can be extrapolated to the "true" $\mathrm{q}_{\infty}$ value for such a plot. Deviations from "straightness of fit" indicate either experimental errors or a process inadequately described by the decay of a single exponential term.

A group of six average to moderately obese subjects was studied under low respiratory circuit volume conditions (18.5 to $21.0 \mathrm{~L}$, Table I, A) and the cyclopropane absorption curves were subjected to this semigraphical exponential analysis. After approximately 3 to 4 hours of absorption, the data in each instance seemed to follow a straight-line fit of a single remaining exponential term. In four of the six subjects the fit was very

fitted by a constant plus one exponential by the same method used here. Of several curve-fitting methods tried, Greville concluded that for his type of data, which were similar to those of the present paper, the present method was the most satisfactory one. good (example, Figure 7, A), while the other two subjects demonstrated slight "kinks" or "oscillations" of the data about a presumed average straight line (example, Figure $7, \mathrm{~B}$ ). The lines were extrapolated to obtain $\mathrm{q}_{\infty}$ absorption values, from which total body fat was calculated.

These straight lines yield not only $\mathrm{q}_{\infty}$, but also a (long) "first" exponential, $\mathrm{a}_{1} \mathrm{e}^{-\mathrm{k}_{1} \mathrm{t}}$. This "peeling off" process was continued, and yielded two further exponential terms within the accuracy of the data. ${ }^{4}$ Three exponential terms were therefore adequate to represent the observed absorption curves in each instance. Since the values derived from these terms were of the same order of magnitude in all subjects, it is felt that the "cyclopropane spaces" and exchange rates implied by these exponentials may have physiological significance.

Total body fat derived from the extrapolated values of $\mathrm{q}_{\infty}$ ranged from 10.7 to $19.7 \mathrm{~kg}$ with a mean of $15.4 \mathrm{~kg}$ (Table III). These values for

4 The "third" exponential term with a half-life of only a few minutes is probably a composite of many very short exponentials, probably including lung and highly perfused organ filling rates. The experimental design permitted only scanty observations over the period required for definition of this exponential, and its values are, at best, a gross average approximation of many rates. In contrast, the much longer "first" exponential term is observed very carefully over many hours, enabling results to be interpreted with greater confidence. 
body fat are in the expected range for the size and habitus of the individual subjects. They may be compared with the respective body fat values calculated indirectly from total body water $[\mathrm{F}(\mathrm{tbw})$, Table III]. In all but one subject, total body fat from cyclopropane absorption $\mathrm{F}$ (exp) was somewhat lower than the $F$ (tbw) value, the mean difference being $2.5 \mathrm{~kg}$ of body fat.

The calculation $F(t b w)$ is an indirect one, involving several numerical assumptions and subtraction of two large numbers to yield a small difference. The error of measurement of total body water in these subjects by dilution of antipyrine or tritium is considered to be \pm 5 per cent. In addition, there is some variation about a 0.72 value for water content of the FFLM. [Keys and Brozek (1) estimate a standard deviation of 0.02 to 0.03 ]. However, there is fairly good evidence that in most mammalian species the mean FFLM hydration value is close to 0.72 . The estimate of total body fat from the calculation : body weight (body water/0.72) is therefore subject to two variables, both randomly distributed. Error analysis of this situation in an individual containing 25 per cent body fat indicates a potential error of about \pm 20 per cent in the estimation of fat mass from body water measurement. This error is, however, of a random nature, rather than the directional one observed in the present comparison (27). It is likely, therefore, that total body fat is being somewhat underestimated by cyclopropane absorption under these conditions.

The inability to apply a single exponential fit closely to the data of large respiratory circuit volume experiments is understandable on theoretical grounds. Considerations based on a theoretical model of gas uptake by the body (Figure 6) and analysis of the present experimental observations indicate that the rate at which the body absorbs cyclopropane from the environment increases as the volume of the closed respiratory circuit becomes smaller. Therefore, the same subject, under identical experimental conditions except for the respiratory circuit volume, will approach gaseous equilibrium more slowly at larger volumes. A change from the "low volume" conditions employed in the present experiments (18.5 to $21.0 \mathrm{~L}$ respiratory circuit volume) to "high volume" conditions (160 to $250 \mathrm{~L}$ volume) should increase the half-life of cyclopropane absorption in body fat about threefold. The addition of fat to the body will also increase the time necessary for approach to equilibrium unless the local supply of blood to body lipids increases approximately proportionately to the increase in lipids. If gas absorption is assumed to follow an exponential rate, these considerations and the experimental observations would indicate the slowest half-life (essentially describing absorption into the lipids) to be roughly 90 to 180 minutes for average subjects under low respiratory circuit volume conditions and about 360 minutes for average subjects under large respiratory circuit volume conditions. Therefore, the normal or slightly obese person studied over an 8 hour period under low volume conditions, has completed about 3 or 4 half-lives of absorption into his "slowest" compartment, minimizing the effect of any minor deviations from an ideal exponential description and enabling relatively accurate extrapolation to a $q_{\infty}$ value.

\section{DISCUSSION}

The preceding analysis of the observed experimental data is based upon an idealized compartment model of inert gas uptake by the body. The exponential analysis follows, with minor modification, the generally accepted theories of such absorption processes $(26,30)$. Application of this analysis to the present experimental observations has led to values for total body fat which are reasonable, but systematically somewhat lower than expected. In addition, the observed deviations from ideal exponential rates are often of greater magnitude than experimental errors, suggesting that one or more of the assumptions involved in setting up the model, or in curve-fitting the data, may not be completely valid. Several of these assumptions may be reviewed.

The steady state. In order to successfully extrapolate a situation such as the present one, the processes involved must go on in more or less constant fashion over the period of observation. In the present instance, we would have to assume constancy of transmision of cyclopropane from the external circuit to the alveolar volume and thence across the pulmonary absorbing surface, constancy of cardiac output and, most particularly, constancy of perfusion of adipose tissue. We have been unable to find published information describ- 
ing any shunting of blood or variation of blood supply to adipose tissues. Gersh and Still (31) noted only 25 to 50 per cent of local fat capillaries of rats to be "open" under the conditions of their study, but whether the "reserve" capillaries are readily available and whether perfusion may vary under the conditions prevalent in our experiments remains speculative. Random changes in blood supply to one or more large depots of fat during an observed absorption experiment would lead to changes in uptake rates of cyclopropane by the tissues involved, and would complicate the mathematical analytical treatment. The "kinks" and

A

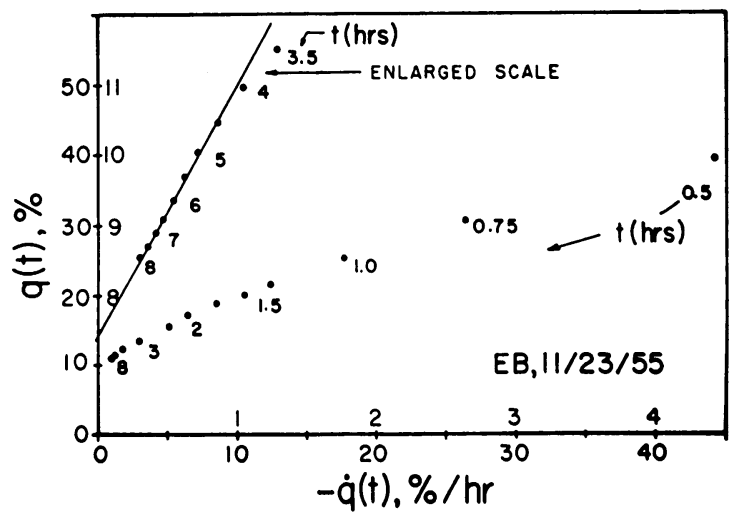

B

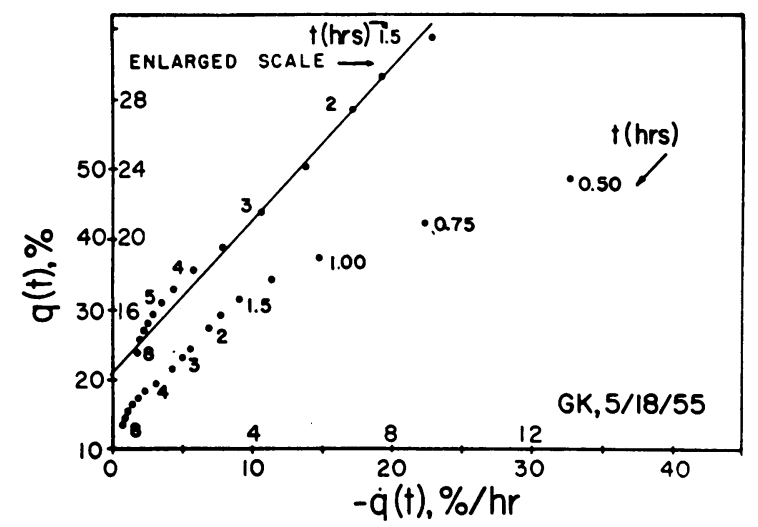

Fig. 7. Examples of exponential Curve-fitting of CYCLOPROPANE ABSORPTION DATA ON NORMAL SUBJECTS (28). At each sampling time, the first derivative (tangent) or $-\dot{q}(t)$ is plotted on the abscissa against the observed $q(t)$ value itself (ordinate). A final single exponential value, if present, can be plotted on a straight line to an equilibrium absorption value $\left(\mathrm{q}_{\infty}\right)$. In each figure the upper points are an enlarged scale of the lower points, and conform to the inner scale on the ordinate.

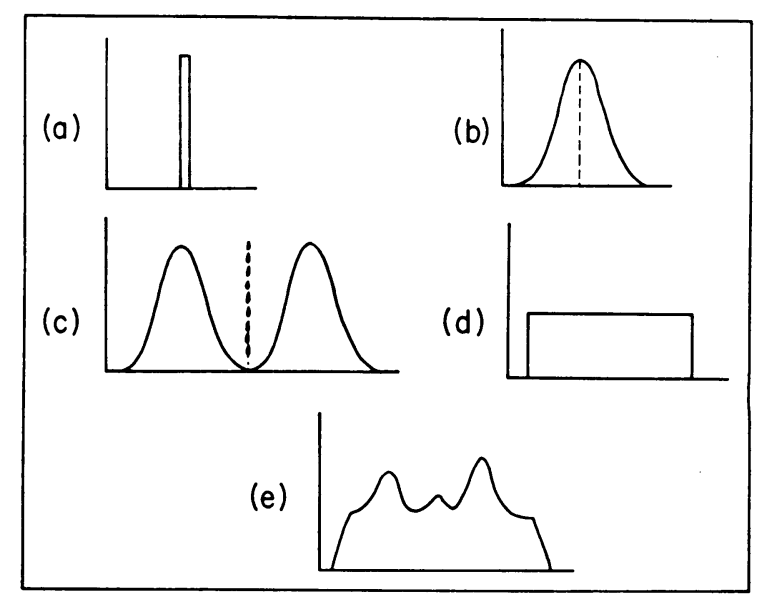

Fig. 8. VARIOUS POSSIBLE SPECTRA OF EQUAL-SIZED SMALL SEGMENTS OF ADIPOSE TISSUE WITH REFERENCE TO THEIR BLOOD SUPPLY. In each diagram the abscissa depicts $F_{1} / V_{1}$, the blood perfusion rate for unit volume of tissue. The ordinate depicts $\mathrm{N}_{1}$, the number of segments so perfused. See text for discussion.

"oscillations" observed in several of the present exponential analyses could be explained by changes in rate of perfusion of fatty tissues and would be difficult to interpret. To our knowledge this problem has not been seriously considered in the past. The possibility that the present simplified mathematical analysis contains a systematic error due to steady state changes cannot be ignored.

Relationship of exponential analysis to perfusion of adipose tissue. The present extrapolation leading to $\mathrm{q}_{\infty}$ was based upon approximating the observed absorption data by a single exponential function at long time (about 4 to 8 hours). The validity of this approximation must be considered. The total fatty tissue in the body may be viewed as a sum of cubes of, for example, $1 \mathrm{~cm}^{3}$ volume. This size cube is selected, since a rough analysis suggests that the internal distances are small enough that diffusion may be considered to be rapid within the cube, while diffusion of cyclopropane from surrounding cubes should be small in comparison with the cyclopropane taken up from the cube's intrinsic blood supply. Thus, the $1 \mathrm{~cm}^{3}$ piece of fatty tissue might be considered as a fundamental perfusion unit, in parallel with many similar units. The relative rate at which the cube fills with an inert gas from an infinite external volume may be expressed as: 


$$
\begin{gathered}
\text { volume of blood flow per minute through the } 1 \mathrm{~cm}^{3} \text { cube }\left(F_{\mathrm{i}}\right) \\
\hline \text { total cyclopropane necessary to "fill" the cube at infinite } \\
\text { time under conditions of the experiment (volume } \times \text { average } \\
\text { solubility coefficient for cyclopropane } \left.=\mathrm{V}_{\mathrm{i}} \lambda_{\mathrm{i}}\right)
\end{gathered}
$$

As the blood flow increases or the tissue solubility decreases, the "filling up" time becomes more rapid. Since solubility can be assumed to be roughly similar in all cubes, the $\lambda_{\mathbf{i}}$ terms are essentially constant and each small segment of fatty tissue can be compared with other such segments solely in terms of relative blood flow rates. In order for all the adipose tissue to absorb cyclopropane at the same rate, each unit would have to be similarly supplied with blood. That this is probably not the case can be inferred from histological examination of subcutaneous, omental, perirenal and other fat depots.

There have been few reports on the blood supply to fatty tissue and even less information is available on relative differences in perfusion rates. If the blood flow to all segments of adipose tissue throughout the body is the same or varies only within a narrow range, the uptake of an inert gas by the total body fat may be described by a single exponential term (Figure 8, a, b). Another possible set of circumstances would be the existence of two or three large groupings of fat units, each group identified by a certain blood flow rate. The single long exponential term derived from the absorption curves of the present experiments would then represent an average of two, or perhaps several, exponential terms which are reasonably closely spaced (Figure $8, \mathrm{c}$ ). If the exponential rates are not too far from one another (i.e., the values for blood perfusion are not too dissimilar for the various groups of units) it would be very difficult to separate the exponential terms and they may appear as a single term (32). If, in fact, multiple exponential rates exist for filling of body fat with cyclopropane, the mistaken single exponential analysis would alter the value for $q_{\infty}$ in the direction necessary to account for the observed systematic discrepancy in body fat values.

Blood perfusion rates of the various segments of fat throughout the body may not lend themselves to grouping about a few values but may instead vary over a wide range (Figure $8, d$ ). Such a situation could not adequately be described by one, or even a few, exponential terms, but rather by a sum of many, or integral of, exponentials with closely spaced half-lives. Such an integral can lead to expressions of, for example, the form $1 / \mathrm{t}^{\mathrm{p}}$.

Diffusion. The assumption has been made that diffusion of gas from capillary blood through each tissue is so rapid that it causes negligible limitation of over-all uptake and also that insignificant diffusion takes place between neighboring tissues. In contrast with studies on gases with less fat solubility $(26,30)$, the conditions present when a very highly lipid-soluble gas (such as cyclopropane) is being absorbed may alter the relative importance of perfusion and diffusion in delivery of gas to body lipids. While diffusion of cyclopropane in aqueous solutions is apparently rapid ( $D \cong 10^{-4}$ to $10^{-5} \mathrm{~cm}^{2}$ per second), it may be slower in living tissues (26). Preliminary studies in this laboratory indicated diffusion constants for cyclopropane in fatty tissues to be $10^{-5}$ to $10^{-7}$ $\mathrm{cm}^{2}$ per second. Diffusion constants of this magnitude are probably not slow enough to cause significant lack of uniformity within an individual depot of fat. However, consideration must also be made of possible diffusion of cyclopropane into fatty tissues from adjacent nonlipid tissues. Without accurate values for diffusion constants of the gas, or for blood perfusion rates, the relative importance of such diffusion cannot be predicted. The analysis of gas diffusion in solving the absorption curves and in extrapolating to $q_{\infty}$ cannot be carried out by a finite sum of exponential functions. The specific expression to be used would depend upon the diffusion constants and upon the geometric relationships of fat and nonfat tissues, which occur in various shapes and sizes.

Thus, at the present state of knowledge, there are several possible methods of mathematical analysis to describe the uptake of a highly fatsoluble inert gas by body lipids. Each method is based upon one or more simplifying hypotheses as to the manner of transport of the gas to the lipids. More exact analysis must await more 
complete knowledge of the geometric arrangement of the various depots of fat tissue, of accurate diffusion constants of the gas through fat tissue and of absolute and relative blood flow rates through various depots of fat. In addition, the existence of a "steady state" of blood flow to body fat must be confirmed, or changes in blood flow measured before more precise analysis is possible.

Despite these gaps in our knowledge, much information can be obtained by the techniques employed. The use of a relatively small respiratory circuit volume (18.5 to $21.0 \mathrm{~L}$ ) appreciably speeds the rate of absorption of inert gases so that over the 8 hour experimental absorption period a normal or moderately obese human subject has completed approximately three to four half-lives of gas absorption into his "slowest" body compartment. Body fat has therefore taken up 80 to 95 per cent of its potential cyclopropane. It is likely that modifications of the present technique can further accelerate gas uptake, leading to even closer approach to equilibrium gas absorption. The extent of absorption provides a favorable analytic situation for extrapolation to the equilibrium $q_{\infty}$ value necessary for calculation of total body fat. This is confirmed by the good results obtained in the present experiments carried out under conditions most favorable for rapid uptake of the inert gas.

The initial interest in developing a direct method for estimating total body fat was to obtain independent values for, and to observe changes in, the fat-free lean mass. Since this mass represents most of the body weight, even moderate error in direct estimation of total body fat will lead to only small error in calculation of the FFLM (FFLM = total body weight - total body fat). The FFLM values calculated from $F$ (cyclo) agreed closely with FFLM values obtained by calculation from total body water (Table IV), the average deviation by the two methods being $2.5 \mathrm{~kg}$, or \pm 5 per cent.

It would appear, therefore, that a method is available for the direct, independent in vivo measurement of total body fat in normal to moderately obese human subjects with reasonable accuracy. From this measurement, accurate values can be derived for FFLM under varying conditions. The method provides a tool which, in conjunction with measurements of total body water, should
TABLE IV

Fat-free lean mass calculated from total body fat by exponential curve-fitting analysis compared with fat-free lean mass calculated from total body water

\begin{tabular}{|c|c|c|c|c|}
\hline & $\begin{array}{l}\text { Subject, } \\
\text { age, sex }\end{array}$ & $W_{1}(t b w) *$ & $\mathrm{~W}_{1}(\exp ) \dagger$ & $\Delta \ddagger$ \\
\hline \multirow[t]{2}{*}{$\begin{array}{l}\text { Normal } \\
\text { fat, } \\
\text { small } \\
\text { resp. } \\
\text { circuit } \\
\text { volume }\end{array}$} & $\begin{array}{l}\mathrm{VL}, 19 \mathrm{~F} \\
\mathrm{GK}, 38 \mathrm{~F} \\
\mathrm{TJ}, 32 \mathrm{M} \\
\mathrm{FK}, 29 \mathrm{M} \\
\mathrm{EB}, 36 \mathrm{M} \\
\mathrm{PD}, 30 \mathrm{M}\end{array}$ & $\begin{array}{r}k g \\
39.0 \\
40.7 \\
53.8 \\
56.1 \\
54.7 \\
54.0\end{array}$ & $\begin{array}{r}k g \\
38.5 \\
42.6 \\
57.1 \\
57.3 \\
57.1 \\
60.6\end{array}$ & \begin{tabular}{r}
\multicolumn{1}{c}{$\%$} \\
-1.28 \\
4.67 \\
6.13 \\
2.14 \\
4.39 \\
12.20
\end{tabular} \\
\hline & Mean & $=49.72$ & 52.20 & 5.13 \\
\hline $\begin{array}{l}\text { Normal } \\
\text { fat, } \\
\text { large } \\
\text { resp. } \\
\text { circuit } \\
\text { volume }\end{array}$ & $\begin{array}{l}\text { VL, } 20 \mathrm{~F} \\
\mathrm{GK}, 39 \mathrm{~F} \\
\mathrm{TJ}, 33 \mathrm{M} \\
\mathrm{RP}, 30 \mathrm{M} \\
\mathrm{PD}, 31 \mathrm{M}\end{array}$ & $\begin{array}{l}39.0 \\
40.7 \\
53.8 \\
54.0 \\
54.0\end{array}$ & $\begin{array}{l}\S \\
\$ \\
\$ \\
\$ \\
\$\end{array}$ & \\
\hline
\end{tabular}

$* \mathrm{~W}_{1}($ tbw $)=$ fat-free lean mass = total body water $/$ 0.72 .

$\dagger \mathrm{W}_{1}(\exp )=$ fat-free lean mass = total body weight - total body fat calculated from exponential analysis of cyclopropane uptake (see Table III).

$\ddagger \Delta=100\left[W_{1}(\exp )-W_{1}(\right.$ tbw $\left.)\right] / W_{1}($ tbw $)$.

$\S$ Analysis by exponential curve-fitting not possible (see text).

permit study of the degree of hydration of the FFLM under normal and certain abnormal conditions and throughout the aging process.

\section{SUMMARY}

A method has been presented for measurement of total body fat in human subjects by absorption of an inert, highly fat-soluble gas from a closed respiratory system. Results are highly reproducible and reflect small changes in fat content. In a group of normal to moderately obese subjects, body fat averaged $15.4 \mathrm{~kg}$, about 12 per cent lower than the fat values for the same subjects calculated indirectly from total body water. The present gas absorption procedure and calculation possibly lead to a systematic underestimation of total body fat.

Since equilibrium of body tissues with cyclopropane in the respiratory system is prolonged in human subjects (longer than 8 hours), observed absorption data were extrapolated to obtain equilibrium values necessary for the calculation of total body fat. Accurate extrapolation requires a mathematical formulation which adequately describes the physiological processes involved. The formulation used here involves a sum of exponential 
terms and coincides with generally accepted theories of inert gas absorption and transport. Data obtained from the present experiments suggest, however, that various aspects of these theories remain open to question. Further knowledge is required of the distribution and nature of blood supply to adipose tissues, of accurate diffusion constants of gases in living tissues and of possibly changing conditions within a given subject which affect the "steady state" before more exact mathematical description (and extrapolation) becomes possible.

By subtraction of measured total body fat from body weight, values may be derived for fat-free lean mass (FFLM). Except for highly obese subjects, total fat is small in relation to body weight and FFLM, and the relative error in the latter calculated value is therefore smaller. Mean FFLM from body fat was $52.2 \mathrm{~kg}$, FFLM calculated from total body water, $49.7 \mathrm{~kg}$.

By the gas absorption technique, fat is being measured directly and essentially independently of the size or condition of the FFLM. It may be utilized, therefore, in conjunction with measurement of total body water, to study changes in hydration of the FFLM that may occur in pathological states and with age.

\section{APPENDIX}

Calculation of total body fat. The experimental data are expressed in terms of the quantity

$$
q(t)=\frac{V_{N} C_{e}(t)}{Q(t)}
$$

in which $\mathrm{C}_{e}(t)$ is the measured concentration of cyclopropane in the sample drawn at time $t$ from a region of the closed respiratory circuit external to the subject (not including the lung volume). This volume will be termed the "external volume". $Q(t)$ is the measured initial amount of cyclopropane introduced into the external volume, minus the measured amount contained in all the samples drawn up to the time $t$, and $V_{N}$ is the external volume plus an effective lung volume (defined below). If the experiment were continued for a length of time sufficient for the body tissues to equilibrate with the cyclopropane concentration in the external volume, $q(t)$ would approach an equilibrium value $\mathrm{q}_{\infty}$ given by

$$
\mathrm{q}_{\infty}=\frac{\mathrm{V}_{\mathrm{N}} \mathrm{C}_{\mathrm{e}}(\infty)}{\mathrm{Q}(\infty)}
$$

in which $\mathrm{C}_{\mathrm{e}}(\infty)$ is defined as the constant concentration of cyclopropane that would exist at sufficiently long time in the external volume and $Q(\infty)$ as the amount of cyclopropane that would exist in the entire system of closed respira- tory circuit and subject at sufficiently long time. In practice a value for $q_{\infty}$ is deduced by extrapolation of the $q(t)$ values measured over a period of approximately 8 hours. The extrapolation is carried out by curve-fitting exponential functions to the data (28). Exponential functions are chosen because they are the mathematical expression of the general compartment model $(32,33)$ which is assumed applicable to the present experiments.

The constant $V_{N}$ is a measure of the external volume plus an effective lung volume for containing inert gas. It is determined by nitrogen dilution (see text) and termed the "respiratory circuit volume." The assumption is made that if this determination were carried out with cyclopropane, the resulting respiratory circuit volume would be the same as for nitrogen. This assumption, which is plausible because of the inert nature and comparable molecular weight of both gases, would be expected, even if not valid, to result in only a small error in the effective lung volume. Such an error is well within the over-all error of measurement of the cyclopropane uptake.

In the cyclopropane uptake experiment a conservation principle using the quantities of Equation [2] can now be applied. The principle states that the amount of cyclopropane initially introduced into the external volume equals the amount leaving the respiratory circuit volume, $\Delta Q_{\text {leav }}$, plus the amount finally remaining in the respiratory circuit volume, or

$$
Q(0)=\Delta Q_{\text {leav }}+V_{N} C_{e}(\infty) .
$$

Now $\Delta Q_{\text {leav }}$ is the amount which goes into the body, $\Delta Q_{\text {body }}$ (the body does not include the effective lung volume), plus the total amount withdrawn in the samples during the experiment, $\Delta Q_{\text {samp. }}$. On the other hand, $Q(0)-\Delta Q_{\text {samp }}$ is the amount remaining in the entire system at long time, $Q(\infty)$. Hence, Equation [3] can be written

$$
Q(\infty)=\Delta Q_{\text {body }}+V_{N} C_{e}(\infty) .
$$

Substituting Equation [4] into Equation [2] and rearranging terms gives

$$
\frac{\Delta Q_{\text {body }}}{\mathrm{V}_{\mathrm{N}} \mathrm{C}_{\mathrm{e}}(\infty)}=\frac{1-\mathrm{q}_{\infty}}{\mathrm{q}_{\infty}} .
$$

A connection is next sought between the amount of cyclopropane absorbed by the body, $\Delta Q_{\text {body, }}$ and the amount of fat contained by the body. To this end, it is assumed that the body is composed additively of two components, $a$ ) total body fat and $b$ ) everything else, termed fat-free lean mass. By this statement is meant not only that the total body weight $\mathrm{W}$ may be written as the sum of a weight of total body fat $W_{f}$ plus a weight of fat-free lean mass $\mathrm{W}_{1}$ or

$$
W_{f}+W_{1}=W
$$

but also that the amount of cyclopropane absorbed by the body at long time can be written as the sum of two terms

$$
\Delta Q_{\text {body }}=W_{f} C_{f^{\prime}}(\infty)+W_{1} C_{1}{ }^{\prime}(\infty)
$$

in which $C_{f}{ }^{\prime}(\infty), C_{1}{ }^{\prime}(\infty)$ are appropriate average concentrations of cyclopropane per unit weight of fat and fat-free lean mass, respectively. (The prime notation denotes per 
unit weight.) Equation [6] can be substantiated, for example, by identifying $W_{f}$ with the weight of etherextractable material from a body and $W_{1}$ with what is left. Equation [7] might be substantiated directly by determining $\mathrm{C}_{\mathrm{f}}{ }^{\prime}(\infty), \mathrm{C}_{\mathrm{l}}{ }^{\prime}(\infty)$ by biopsy measurements of various body tissues and using the values $W_{f}, W_{1}$ obtained independently by ether extraction. One could also use the more indirect consequences of Equation [7] as determined below to compare with ether-extracted values. Such comparison has been made for the rat (17), and indicates the validity of Equation [7].

The concentrations $\mathrm{C}_{\mathrm{f}}{ }^{\prime}(\infty), \mathrm{C}_{\mathrm{l}}{ }^{\prime}(\infty)$ of cyclopropane in the body at sufficiently long time, that is, at equilibrium, are next related to the equilibrium concentration $\mathrm{C}_{\mathrm{e}}(\infty)$ in the external volume. For brevity the notation $(\infty)$ is dropped. All concentrations are assumed to be equilibrium values. Consider first $\mathrm{C}_{\mathrm{f}}{ }^{\prime}$. Write

$$
\frac{\mathrm{C}_{\mathrm{f}}{ }^{\prime}}{\mathrm{C}_{\mathrm{e}}}=\frac{\mathrm{C}_{\mathrm{f}}{ }^{\prime}}{\mathrm{C}_{\mathrm{A}}} \frac{\mathrm{C}_{\mathrm{A}}}{\mathrm{C}_{\mathrm{e}}}
$$

where $C_{A}$ is the equilibrium concentration (per unit volume) of cyclopropane in the alveolar spaces of the lung. The body fat is assumed to be in thermodynamic equilibrium with the gases in the alveolar spaces via the mediation of the circulating blood. Hence, the ratio $C_{f}{ }^{\prime} / C_{A}$ can be expressed in terms of a solubility coefficient $\alpha_{\mathrm{f}}{ }^{\prime}$ of cyclopropane in fat as

$$
\frac{\mathrm{C}_{\mathrm{f}}{ }^{\prime}}{\mathrm{C}_{\mathrm{A}}}=\alpha_{\mathrm{f}}{ }^{\prime} \frac{\mathrm{T}_{\mathrm{A}}}{273}
$$

where $\alpha_{\mathrm{f}}{ }^{\prime}$ is in milliliters STP of cyclopropane per gram of fat, and $T_{A}$ is the absolute temperature in the alveolar volume. The concentration ratio $\mathrm{C}_{1}{ }^{\prime} / \mathrm{C}_{\mathrm{A}}$ can be similarly expressed as

$$
\frac{\mathrm{C}_{1}{ }^{\prime}}{\mathrm{C}_{\mathrm{A}}}=\alpha_{1}{ }^{\prime} \frac{\mathrm{T}_{\mathrm{A}}}{273}
$$

The solubility coefficients $\alpha_{\mathrm{f}}{ }^{\prime}, \alpha_{1}{ }^{\prime}$ per gram of tissue are used here instead of the more conventional Bunsen solubility coefficients $\alpha_{\mathrm{f}}, \alpha_{1}$ per milliliter of tissue because the former were measured $(17,21)$, making knowledge of the density of the body fat unnecessary.

The concentration of cyclopropane, $\mathrm{C}_{\mathrm{A}}$, in the alveolar volume, $V_{A}$ must next be related to the concentration $C_{e}$ in the external volume. ${ }^{5}$ In the alveolar volume $V_{A}$, the temperature $T_{A}$ and water vapor pressure $p_{v A}$ differ slightly from the corresponding quantities $T_{e}, p_{v e}$ in the external volume $\mathrm{V}_{\mathrm{e}}$. Also, the concentration of nitrogen is somewhat greater in the alveolar volume than in the external volume because the rate of expiration of carbon dioxide is less than the rate of inspiration of oxygen (the respiratory quotient effect) (34). It can be shown, using the perfect gas law, the condition of equal total pressure in external and alveolar volume, and the approximate value for con-

5 From the standpoint of concentration, the respiratory dead space volume is a transitional region between the external volume and the alveolar volume. This dead space volume may be considered, for the present purposes, to be suitably divided between the external and alveolar volumes. It is included in the measurement of respiratory circuit volume. centration ratio of nitrogen between alveolar volume and external volume $\left[\mathrm{N}_{2}\right]_{\mathrm{M}} /\left[\mathrm{N}_{2}\right]_{\mathrm{e}}=80 / 79$ that

$$
\frac{\mathrm{C}_{\mathrm{A}}}{\mathrm{C}_{\mathrm{e}}}=\frac{80}{79} \frac{\mathrm{T}_{\mathrm{e}}}{\mathrm{T}_{\mathrm{A}}}\left(\frac{\mathrm{p}_{\mathrm{e}}-\mathrm{p}_{\mathrm{vA}}}{\mathrm{p}_{\mathrm{e}}-\mathrm{p}_{\mathrm{ve}}}\right) \text {. }
$$

Equations [7] to [11] can now be substituted into Equation $[5]$ to yield

where

$$
\alpha_{\mathrm{f}}^{\prime} \mathrm{W}_{\mathrm{f}}+\alpha_{\mathrm{l}}{ }^{\prime} \mathrm{W}_{1}=\alpha^{\prime} \mathrm{W}^{\prime}
$$

$$
\alpha^{\prime} W=\left(\frac{79}{80}\right)\left(\frac{273}{T_{e}}\right)\left(\frac{p_{e}-p_{v e}}{p_{e}-p_{v A}}\right)\left(\frac{1-q_{\infty}}{q_{\infty}}\right) V_{N}
$$

The quantity $\alpha^{\prime} \mathrm{W}$ defined by Equation [13] is expressed in terms of quantities determined by the experiment. The physical interpretation of this quantity is given by the left hand side of Equation [12] as the number of milliliters STP of cyclopropane absorbed by the body if the body is held in solubility contact with a reservoir at body temperature containing cyclopropane at one atmosphere pressure (if $W_{f}, W_{1}$ are expressed in grams and $\alpha_{\mathrm{f}}{ }^{\prime}, \alpha_{1}{ }^{\prime}$ in milliliters STP cyclo per gram of tissue). Hence, the quantity $\alpha^{\prime}$ is an average solubility coefificient for the body as a whole.

The solubility equation [12] can now be solved simultaneously with the body weight equation [6] to yield $W_{\mathrm{f}}$ and $W_{1}$. Thus,

$$
\begin{aligned}
& \frac{W_{\mathrm{f}}}{W}=\frac{\alpha^{\prime}-\alpha_{\mathrm{l}}{ }^{\prime}}{\alpha_{\mathrm{f}}{ }^{\prime}-\alpha_{\mathrm{l}}{ }^{\prime}} \\
& \frac{W_{\mathrm{l}}}{\mathrm{W}}=\frac{\alpha_{\mathrm{f}}{ }^{\prime}-\alpha^{\prime}}{\alpha_{\mathrm{f}}{ }^{\prime}-\alpha_{\mathrm{l}}{ }^{\prime}}
\end{aligned}
$$

The form of Equations [14] and [15] exhibits the analogy between the solubility method and the densitometric method (1) of determining total body fat. It is useful, also, to solve Equations [12] and [13] for $q_{\infty}$. The result is

$$
\mathrm{q}_{\infty}=\frac{\mathrm{V}_{0}^{\prime}}{\mathrm{V}_{0}^{\prime}+\alpha_{\mathrm{f}} \mathrm{W}_{\mathrm{f}}+\alpha_{\mathrm{l}}^{\prime} W_{\mathrm{l}}}
$$

where $V_{0}^{\prime}$ is defined as

$$
V_{0}^{\prime}=\left(\frac{79}{80}\right)\left(\frac{273}{T_{e}}\right)\left(\frac{p_{e}-p_{v e}}{p_{e}-p_{v A}}\right) V_{N} .
$$

The following solubility coefficients for cyclopropane in total body fat and in fa-free lean mass, at a temperature of $36 \pm 1^{\circ} \mathrm{C}$, were used:

$$
\begin{aligned}
\alpha_{\mathrm{f}}{ }^{\prime} & =11.26 \pm 0.40 \mathrm{~L} \text { cyclo STP per kg fat }{ }^{6} \\
\alpha_{1}{ }^{\prime} & =\left(0.46 \pm 0.10 \frac{\mathrm{L} \text { cyclo STP }}{\mathrm{L} \text { body water }}\right)^{7} \\
& \times\left(0.72 \pm 0.03 \frac{\mathrm{L} \text { body water }}{\mathrm{kg} \text { fat-free lean mass }}\right)^{8}
\end{aligned}
$$

6 This value is an average of measurements made on pooled rat fat (21). Later results on fat samples from humans varied only slightly from those on pooled rat fat (35).

${ }^{7}$ Estimated from measurements on various solutions of water, protein and salts (17).

${ }^{8}$ Summary of many experiments critically reviewed by Keys and Brozek (1). 
or,

$\alpha_{\Lambda}^{\prime}=0.33 \pm 0.073 \mathrm{~L}$ cyclo STP

per $\mathrm{kg}$ fat-free lean mass.

Total body fat $W_{f}$ and fat-free lean mass $W_{1}$ were calculated by Equations [14] and [15] for those experiments in which $\mathrm{q}_{\infty}$ could be derived. The basic data used in the calculations, aside from the solubility coefficients, Equations [18] and [19], are given in Tables I, II and III. In determining the values of $\alpha^{\prime}$ by Equation [13] the following temperature and pressure values were used: $T_{e}, p_{c}$ average temperature and pressure, respectively, in the last 2 hours of each experiment (maximal deviation from these values less than 1 per cent), $\mathrm{p}_{\mathrm{vA}}=47 \mathrm{~mm} \mathrm{Hg}, \mathrm{p}_{\mathrm{ve}}=0.80$ $X$ water vapor pressure at temperature $T_{e},\left(p_{v e} \approx 23 \mathrm{~mm}\right.$ $\mathrm{Hg}$ ). The results are given in Tables III and IV. The values of $\mathrm{q}_{\infty}(\mathrm{tbw})$ in Table III were calculated by Equation [16] using $W_{1}=$ (total body water)/0.72 and $W_{f}$ $=\mathrm{W}-\mathrm{W}_{\mathrm{l}}$.

Accuracy of cyclopropane uptake method. The accuracy of total body fat and fat-free lean mass determination by the cyclopropane uptake method can be estimated by Equations [14] and [6]. Consider a case with $W_{f} / W$ $=0.2, \mathrm{~W}_{1} / \mathrm{W}=0.8$, which requires a whole body solubility coefficient $\alpha^{\prime}=2.52$ by Equation [12]. An uncertainty of \pm 15 per cent is assigned to this number, giving $\alpha^{\prime}=2.52 \pm 0.378$. This uncertainty, due essentially to uncertainty in $\mathrm{q}_{\infty}$ (see Equation [13]), was obtained by tripling the partial uncertainty in $\mathrm{q}_{\infty}$ estimated in curvefitting the experimental $q(t)$ data by a sum of exponential functions (28). The preceding numbers and those for $\boldsymbol{\alpha}_{\mathrm{f}}{ }^{\prime}, \boldsymbol{\alpha}_{1}{ }^{\prime}$ yield, in Equation [14],

$$
\begin{aligned}
\frac{W_{f}}{W} & =\frac{(2.52 \pm 0.378)-(0.33 \pm 0.073)}{(11.26 \pm 0.40)-(0.33 \pm 0.073)} \\
& =\frac{2.19 \pm 0.385}{10.93 \pm 0.407}=\frac{2.19(1 \pm 0.176)}{10.93(1 \pm 0.0372)} \\
& =0.20(1 \pm 0.180)=0.20 \pm 0.036
\end{aligned}
$$

and, by Equation [6]

$$
\begin{aligned}
\frac{\mathrm{W}_{1}}{\mathrm{~W}}=1-\frac{\mathrm{W}_{\mathrm{f}}}{\mathrm{W}}=1-0.20 \pm & 0.036 \\
& =0.80(1 \pm 0.045) .
\end{aligned}
$$

Thus, for a normal subject the cyclopropane uptake method in its present state of development gives an estimated uncertainty of \pm 18 per cent for total body fat and \pm 5 per cent for fat-free lean mass.

The primary source of uncertainty in the cyclopropane uptake method is the uncertainty of 15 per cent assigned to $\alpha^{\prime}$ and due essentially to a like uncertainty in $q_{\infty}$. If this uncertainty can be reduced to 5 per cent, as is thought possible, then the uncertainty in the body fat value would be reduced to about 8 per cent and in fat-free lean mass value to about 2 per cent. This accuracy would be achieved despite an uncertainty of about 3.5 per cent in $\alpha_{f}^{\prime}$ and of the large uncertainty of about 21 per cent in $\alpha_{1}{ }^{\prime}$. The latter uncertainty has little influence because $\alpha_{l}^{\prime}$ is quite small relative to $\boldsymbol{\alpha}_{\mathbf{f}}$.
More generally, the fractional error in $\mathrm{W}_{\mathrm{f}}$ is obtained from Equation [14] by differentiation and root mean square addition of random errors as

$$
\frac{\delta W_{f}}{W_{f}}=\left[\frac{\left(\delta \alpha^{\prime}\right)^{2}+\left(\delta \alpha_{1}\right)^{2}}{\left(\alpha^{\prime}-\alpha_{1}^{\prime}\right)^{2}}+\frac{\left(\delta \alpha_{\mathrm{f}}\right)^{2}+\left(\delta \alpha_{1}\right)^{2}}{\left(\alpha_{\mathrm{f}}{ }^{\prime}-\alpha_{1}^{\prime}\right)^{2}}\right]^{\frac{1}{2}}
$$

and by Equation [6],

$$
\frac{\delta W_{1}}{W_{1}}=\frac{W_{f}}{W_{1}} \frac{\delta W_{f}}{W_{f}}
$$

where $\delta \alpha^{\prime}$ is the uncertainty in $\alpha^{\prime}$, and so forth. Equation [22] indicates that unless total body fat is less than about 5 per cent of body weight, the main error in the total body fat is due to uncertainty in $\alpha^{\prime}$, i.e., uncertainty in $\mathrm{q}_{\infty}$. Below this range, error in $\alpha_{1}{ }^{\prime}$ becomes important.

\section{ACKNOWLEDGMENTS}

The authors appreciatively note the competent assistance and constructive suggestions provided by Miss Mildred Holder and Miss Mu-Wan Sun. Miss Edith Schreiber and Mrs. Renate Galli assisted in the computations, Miss Catherine Tasso in editing and typing.

\section{REFERENCES}

1. Keys, A., and Brozek, J. Body fat in adult man. Physiol. Rev. 1953, 33, 245.

2. Behnke, A. R., Jr. Physiologic studies pertaining to deep sea diving and aviation, especially in relation to the fat content and composition of the human body. Harvey Lect. 1941-2, 37, 198.

3. Morales, M. F., Rathbun, E. N., Smith, R. E., and Pace, N. Studies on body composition. II. Theoretical considerations regarding the major body tissue components, with suggestions for application to man. J. biol. Chem. 1945, 158, 677.

4. Kraybill, H. F., Hankins, O. G., and Bitter, H. L. Body composition of cattle. I. Estimation of body fat from measurement in vivo of body water by use of antipyrine. J. appl. Physiol. 1951, 3, 681.

5. Messinger, W. J., and Steele, J. M. Relationship of body specific gravity to body fat and water content. Proc. Soc. exp. Biol. (N. Y.) 1949, 70, 316.

6. Osserman, E. F., Pitts, G. C., Welham, W. C., and Behnke, A. R. In vivo measurement of body fat and body water in a group of normal men. J. appl. Physiol. 1950, 2, 633.

7. Hastings, A. B., and Eichelberger, L. The exchange of salt and water between muscle and blood. I. The effect of an increase in total body water produced by the intravenous injection of isotonic salt solutions. J. biol. Chem. 1937, 117, 73.

8. Miller, A. T., Jr., and Blyth, C. S. Lean body mass as a metabolic reference standard. J. appl. Physiol. 1953, 5, 311.

9. Steele, J. M., Brodie, B. B., Messinger, W. J., Soberman, R. J., Berger, E. Y., and Galdston, M. The relationship of body water to basal metabolic 
rate and surface area. Trans. Ass. Amer. Phycns $1949,62,214$.

10. Moulton, C. R. Age and chemical development in mammals. J. biol. Chem. 1923, 57, 79.

11. Pace, N., and Rathbun, E. N. Studies on body composition. III. The body water and chemically combined nitrogen content in relation to fat content. J. biol. Chem. 1945, 158, 685.

12. Widdowson, E. M., McCance, R. A., and Spray, C. M. The chemical composition of the human body. Clin. Sci. 1951, 10, 113.

13. Soberman, R., Brodie, B. B., Levy, B. B., Axelrod, J., Hollander, V., and Steele, J. M. The use of antipyrine in the measurement of total body water in man. J. biol. Chem. 1949, 179, 31.

14. Siri, W. E. The gross composition of the body. Advanc. biol. med. Phys. 1956, 4, 239.

15. Shaw, L. A., Behnke, A. R., Messer, A. C., Thomson, R. M., and Motley, E. P. The equilibrium time of the gaseous nitrogen in the dog's body following changes of nitrogen tension in the lungs. Amer. J. Physiol. 1935, 112, 545.

16. Behnke, A. R., Thomson, R. M., and Shaw, L. A. The rate of elimination of dissolved nitrogen in man in relation to the fat and water content of the body. Amer. J. Physiol. 1935, 114, 137.

17. Lesser, G. T., Blumberg, A. G., and Steele, J. M. Measurement of total body fat in living rats by absorption of cyclopropane. Amer. J. Physiol. 1952, 169, 545 .

18. Waters, R. M., and Schmidt, E. R. Cyclopropane anesthesia. J. Amer. med. Ass. 1934, 103, 975.

19. Robbins, B. H. Studies of cyclopropane. I. The quantitative determination of cyclopropane in air, water, and blood by means of iodine pentoxide. J. Pharmacol. exp. Ther. 1936, 58, 243.

20. Robbins, B. H. Cyclopropane Anesthesia, 2nd ed. Baltimore, Williams and Wilkins, 1958, p. 9.

21. Blumberg, A. G., LaDu, B. N., Jr., Lesser, G. T., and Steele, J. M. The determination of the solubility of cyclopropane in fats and oils with the use of the Warburg apparatus. J. Pharmacol. exp. Ther. 1952, 104, 325.
22. Eichna, L. W., Berger, A. R., Rader, B., and Becker, W. H. Comparison of intracardiac and intravascular temperatures with rectal temperatures in man. J. clin. Invest. 1951, 30, 353.

23. Hart, J. S. Average body temperature in mice. Science 1951, 113, 325.

24. Burton, A. C. Human calorimetry. II. The average temperature of the tissues of the body. J. Nutr. 1935, 9, 261.

25. Jones, H. B. Preoxygenation and nitrogen elimination in Studies on Gas Exchange. U. S. Air Force, Aero Med. Lab. Memorandum Report MCREXD696-114, 1948, pp. 7-102.

26. Kety, S. S. The theory and applications of the exchange of inert gas at the lungs and tissues. Pharmacol. Rev. 1951, 3, 1.

27. Lesser, G. T., Blumberg, A. G., and Steele, J. M. Measurement of total body fat in man by absorption of cyclopropane in Biochem. Problems of Lipids. Proc. of Second Int. Conf. on Biochemistry, G. Popjak and E. Le Breton, Eds. London, Butterworth Sci. Publ., 1956, pp. 373-384.

28. Perl, W. A method for curve-fitting by exponential functions. Int. J. appl. Radiat. In press.

29. Greville, G. D. The intravenous glucose tolerance equation. Biochem. J. 1943, 37, 17.

30. Jones, H. B. Respiratory system: Nitrogen elimination in Medical Physics, O. Glasser, Ed. Chicago, The Yearbook Publ., 1950, vol. 2, p. 855-71.

31. Gersh, I., and Still, M. A. Blood vessels in fat tissue. Relation to problems of gas exchange. J. exp. Med. 1945, 81, 219.

32. Sheppard, C. W., and Householder, A. S. Mathematical basis of interpretation of tracer experiments in closed steady-state systems. J. appl. Physiol. 1951, 22, 510.

33. Robertson, J. S. Theory and use of tracers in determining transfer rates in biological systems. Physiol. Rev. 1957, 37, 133.

34. Comroe, J. H., Jr., Forster, R. E., II, Dubois, A. B., Briscoe, W. A., and Carlsen, E. The Lung. Chicago, The Year Book Publishers Inc., 1955, p. 48.

35. Nidus, B., and Lesser, G. T. Unpublished data. 